The International Journal Of Engineering And Science (IJES)

|| Volume || 6 || Issue || 1 || Pages || PP 17-23 || 2017 ||

ISSN (e): 2319 - 1813 ISSN (p): $2319-1805$

THE IJES

\title{
Optimal Economic Load Dispatch of the Nigerian Thermal Power Stations Using Particle Swarm Optimization (PSO)
}

\author{
Y. S. Haruna ${ }^{1}$, Y. A. Yisah², G. A. Bakare ${ }^{1}$, M. S. Haruna ${ }^{3}$ and S. O. Oodo ${ }^{3}$ \\ ${ }^{I}$ Department of Electrical and Electronics Engineering, A. T. B. U Bauchi-Nigeria, \\ ${ }^{2}$ Power Equipment and Electrical Machinery Development Institute (PEEMADI), P.M.B. 1029, Okene, Kogi State. \\ ${ }^{3}$ Department of Electrical and Electronics Engineering, Nile University of Nigeria, Abuja.
}

\begin{abstract}
This paper deals with the optimization of economic load dispatch (ELD) problem; this is to find the optimal combination of generators in order to minimize the operating costs of the system. This is done by using the particle swarm optimization (PSO) algorithm. PSO is applied to search for the optimal schedule of all the generator units that can supply the required demand at minimum fuel cost while satisfying all system constraints. The PSO algorithm has been implemented using MATLAB optimization toolbox and was applied to solve the ELD problem of the Nigeria thermal power stations. The results were compared with published results obtained via micro-GA, conventional-GA and differential evolution (DE) techniques.
\end{abstract}

Keywords: Economic Load Dispatch, Particle Swarm Optimization and Nigeria Thermal Power Stations.

Date of Submission: 28 December 2016

Date of Accepted: 20 January 2017

\section{INTRODUCTION}

The modern power system around the world has grown in complexity of interconnection and power demand. The focus has shifted towards the enhanced performance, increased customer focus, low cost, reliable and clean power. In this changed perspective, scarcity of energy resources, increasing power generation cost, environmental concern necessitates optimal economic load dispatch (ELD). In reality power stations neither are at equal distances from load nor have similar fuel cost functions. Hence for providing cheaper power, load has to be distributed among the various power stations in a way which results in lowest cost of generation [1].

The main aim of electric power utilities is to provide high-quality, reliable power supply to the consumers at the lowest possible cost while operating to meet the limits and constraints imposed on the generating units. This formulates the economic load dispatch (ELD) problem for finding the optimal combination of the output power of all the online generating units that minimizes the total fuel cost, while satisfying an equality constraint and a set of inequality constraints. As the cost of power generation is exorbitant, an optimum dispatch results in economy [2].

Traditional algorithms like lambda iteration, base point participation factor, gradient method, and Newton method can solve this ELD problems effectively if and only if the fuel-cost curves of the generating units are piece-wise linear and monotonically increasing. Practically the input-output characteristics of the generating units are highly non-linear, non-smooth and discrete in nature owing to prohibited operating zones, ramp rate limits and multi fuel effects. Thus the resultant ELD becomes a challenging non-convex optimization problem, which is difficult to solve using the traditional methods $[3,4]$.

Several heuristic approaches like evolutionary programming (EP), genetic algorithm (GA), ant colony search (ACS), tabu search (TS), artificial neural network (ANN), bio-geography based optimization (BBO), differential evolution (DE) and simulated annealing (SA) have been developed for solving both linear and non-linear ED problems [5-8].

In this paper, particle swarm optimization (PSO) algorithm is proposed to solve the ELD problems in power systems. The viability of the method is analyzed for its accuracy and rate of convergence on the Nigerian power network (1999 model) and results were compared with other heuristics methods.

\subsection{Nigerian Power System}

The electricity demand in Nigeria far outstrips the supply and the supply is epileptic in nature. This is hindering its development, notwithstanding the availability of vast natural resources in the country. Constant power supply is the hallmark of a developed economy. Any nation whose energy need is epileptic in supply prolongs her development and risks losing potential investors.

Reliable Power production is critical to the profitability of electricity utilities. This can only be realized when the power generators are scheduled efficiently to meet electricity demand. Economic load dispatch have been applied to obtain optimal fuel cost while satisfying systems system constraints and generator scheduling for 
hourly anticipated load within a period of 24 hours. The efficiency of generating unit, the transmission looses and the operating costs are important factors to be considered for the economic operation of the system.

In recent years, the Power Holding Company of Nigeria (PHCN) has been experiencing serious problem in generation, transmission, distribution, maintenance, financial constraints and increase in power demand [9], considering the generation/power demand problems, several units were on emergency/forced outages, which led to system disturbance such as; partial and total system collapse. These problems were attributed to over stressing the units to generate outside their normal operating conditions. This will thus lead to generating electric power at loss.

In view of the above problem, it becomes necessary for one to study the cost functions of the available thermal units, their power limits and the maximum power demand of the whole country at a particular time so as to carry out the ELD problem.

The aim of this research is to apply a particle swarm optimization technique to solve the economic load dispatch (ELD) problem; for the purpose of optimal allocation of the total power demand among the available generating units that minimizes the total generation cost subject to specified system constraints.

\subsection{Statement of the Problem}

Consider a system consisting of $\mathrm{N}$ thermal units connected to a transmission network as shown in Figure 1 below.

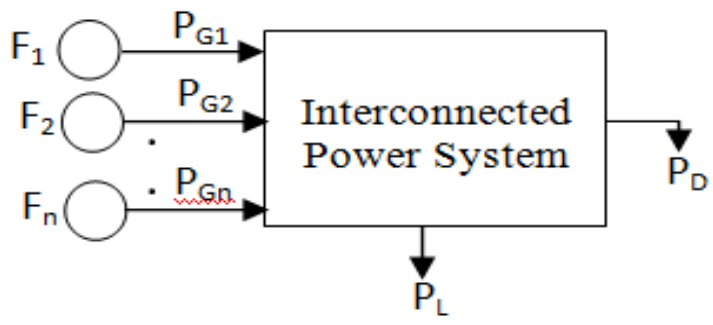

Figure 1: Interconnected Power System Network

Where, $F_{i}=$ fuel cost of unit $i$,

$P_{G_{i}}=$ power delivered by unit $i$,

$P_{D}=$ total power demand and

$P_{L}=$ total power loss.

The quadratic cost function of unit $\boldsymbol{i}$, is given by;

$$
F_{i}\left(P_{G_{i}}\right)=\alpha_{i}+\beta_{i} P_{G_{i}}+\gamma_{i} P_{G_{i}}^{2}
$$

Where, $\alpha_{i}$ - Constant cost coefficient of unit $i$,

$\beta_{i}$-Linear constant cost coefficient of unit $i$

$\gamma_{i}$-A quadratic constant cost coefficient of unit $i$.

Operating the system subject to generation constraints, this objective function can be expressed mathematically as:

$$
F_{T}=\sum_{i=1}^{N} F_{i}\left(P_{G_{i}}\right) \quad i=1,2 \ldots \ldots . \mathrm{N}
$$

Where, $F_{T}$ is the total cost of power generation and

$$
F_{i}\left(P_{G_{i}}\right) \text { is the generation cost of unit } i \text {. }
$$

The ELD problem seeks to find the optimal combination of thermal power generations that minimized the total cost while satisfying the total power demand and the systems constraints. The ELD problem is formulated as minimization of Eqn. (2) subject to the following constraints:

\subsubsection{Equality constraints}

$$
\sum_{i=1}^{N} P_{G_{i}}=P_{D}+P_{L}
$$

Using the B-coefficient method, network losses are expressed as: 


$$
P_{L i}=P_{G i}^{T}[B] P_{G i}
$$

Where, $[B]$ is the B matrix coefficient.

\subsubsection{Inequality constraints}

$$
P_{G i}^{\mathrm{min}} \leq P_{G i} \leq P_{G i}^{\mathrm{max}}
$$

Where, $P_{G i}^{\mathrm{m} i \mathrm{n}}$ is the minimum power limits of the unit $i$

$P_{G i}^{\mathrm{max}}$ is the maximum power limits of unit $i$.

Finally, PSO was applied to the coordination of the Nigerian thermal power plants. This research on economic load dispatch is modeled using the quadratic cost function. The issues of environmental constraints, generation ramp-rate limits, valve-point effect and piecewise linear cost function are out of scope of this paper.

\section{LITERATURE REVIEW}

The ELD problem has been widely studied and reported by different authors. The techniques used in the literature ranges from the classical optimization techniques to the recent meta- heuristic optimization techniques such as evolutionary algorithms (EA), genetic algorithm (GA), simulated annealing (SA) and particle swarm optimization (PSO).

[3] developed a Pareto frontier Differential Evolution (PDE) technique to solve MOED problem. The proposed method was implemented on the standard IEEE-30 bus system having six generating units including valve point effects to evaluate its performance and applicability. From the results obtained, the proposed method demonstrated its effectiveness by solving the Multi Objective economic dispatch problem considering security constraints.

[4] proposed and developed evolutionary algorithms to solve the economic dispatch problem for the optimum performance of a nonlinear and complex systems. They considered all the constraints of power dispatch for economic operation of the power system.

[5] presented the economic power dispatch problems using ant colony optimization (ACO) technique which is a meta-heuristic approach for solving hard combinatorial optimization problems. This technique was tested using the standard IEEE 26-Bus RTS and the results revealed that the proposed technique has the merit in achieving optimal solution for addressing the problems. Comparative studies with artificial immune system (AIS) were also conducted in order to highlight the strength of the proposed technique.

In the year 2012, [6] presented an effective and reliable particle swarm optimization (PSO) technique for the economic load dispatch problem using the standard 3-generator and 6-generator systems with and without consideration of transmission losses. The final results obtained using PSO are compared with conventional quadratic programming and found to be encouraging.

[7] proposed a method for solving economic dispatch problem using Particle Swarm Optimization (PSO) Algorithm and Simulated Annealing (SA) for the three generating units as a case study. PSO and SA were applied to find out the minimum cost for different power demand. They compared their results with the traditional technique, where PSO displayed better result and better convergence characteristic.

[8] presented an improved exponential harmony search algorithm for improving the HS algorithm to solve the SELD problem considering the valve-point effect. The numerical results show that the proposed method has better convergence and also lower production costs than the conventional HS and particle swarm optimization methods.

[10] presented the overview of different methods for solving economic load dispatch (ELD) problem using MATLAB. They concluded that lambda iteration method converges rapidly but complexities increases as system size increase. Gradient and newton methods can only be applied where cost function is much more complex while for the non convex input-output curves, dynamic programming method can be used to solve the economic load dispatch problem.

[11] presented lambda iteration method to solve the ELD problem using MATLAB for the three and six generating units with and without transmission losses.

[12] presented an application of the GAMS method to power economic dispatch (PED) problem with Power loss for 3 and 6 generator test case systems. The simulation results show that the proposed GAMS Method outperforms previous optimization methods.

\subsection{Heuristic Optimization Techniques}

As an alternative to the conventional mathematical approaches, the heuristic optimization techniques such as genetic algorithms, Tabu search, simulated annealing, and recently introduced particle swarm optimization 
(PSO) are considered as realistic and powerful solution schemes to obtain the global optimums in power system optimization problems.

\subsection{Particle Swarm Optimization}

Particle swarm optimization was first introduced by Kennedy and Eberhart in the year 1995. It is an exciting new methodology in evolutionary computation and a population-based optimization tool. PSO is motivated from the simulation of the behaviour of social systems such as fish schooling and birds flocking. The PSO algorithm requires less computation time and less memory because of its inherent simplicity [7].

The basic assumption behind the PSO algorithm is that birds find food by flocking and not individually. This leads to the assumption that information is owned jointly in the flocking. The swarm initially has a population of random solutions. Each potential solution, called a particle (agent), is given a random velocity and is flown through the problem space.

All the particles have memory and each particle keeps track of its previous best position (pbest) and the corresponding fitness value. The swarm has another value called gbest, which is the best value of all the pbest. Particle swarm optimization has been found to be extremely effective in solving a wide range of engineering problems and solves them very quickly.

\section{APPLICATION OF PSO IN ELD}

The aim of this research is to distribute the total power demand among the available thermal generating stations to minimizing the total fuel cost subject to both equality and inequality constraints as earlier stated in Eqns. 1-3. Particle Swarm Optimization was used to achieve this desired goal.

The solution of the ELD problem using the classical approach presents some limitation in its implementation. One of such limitation is that the Lamda-iteration method assumes the cost coefficient to be a continuous function. The method breaks down when it is applied to a discontinuous function with prohibited zones or larger steam turbine generating units [13]. Also, there is a large tendency for this approach to converge at a local minimum when the power system operating status is far outside the normal situation, for instance during and after large disturbances. For this purpose, the Particle Swarm Optimization technique was applied in this paper to solve an ELD problem in order to eliminate the limitation of the Lamda-iterations enumerated above.

In a PSO system, population of particles exists in the n-dimensional search space. Each particle has certain amount of knowledge and will move about the search space on the basis of this knowledge. The particle has some inertia attributed to it and hence will continue to have a component of motion in the direction it is moving. The Particle knows its location in the search space and will encounter with the best solution. The particle will then modify its direction such that it has additional components towards its own best position, pbest and towards the overall best position, gbest. The particle updates its velocity and position using the following Eqn. (6) and (7).

$$
\begin{aligned}
& V_{i}^{(k+1)}=w V_{i}^{k}+c_{1} \operatorname{Rand}_{1}() \times\left(\text { pbest }_{i}-S_{i}^{k}\right)+c_{2} \text { Rand }_{2}() \times\left(\text { gbest }_{i}-S_{i}^{k}\right) \\
& S_{i}^{(k+1)}=S_{i}{ }^{K}+V_{i}{ }^{(k+1)}
\end{aligned}
$$

Where, $V_{i}^{k}$ is the velocity of individual $\mathrm{i}$ at iteration $k$,

$\mathrm{k}$ is pointer of iterations,

$\mathrm{W}$ is the weighing factor,

$C_{1}, C_{2}$ are the acceleration coefficients,

$\operatorname{Rand}_{1}\left(\right.$ ), $\operatorname{Rand}_{2}$ ( ) are the random numbers between and 1,

$\mathrm{S}^{\mathrm{k}}$ is the current position of individual $\mathrm{i}$ at iteration $\mathrm{k}$,

pbest $_{\mathrm{i}}$ is the best position of individual $i$ and

gbest is the best position of the group.

The coefficients $C_{1}$ and $C_{2}$ pull each particle towards pbest and gbest positions. Low values of acceleration coefficients allow particles to roam far from the target regions, before being tugged back. Hence, the acceleration coefficients $\mathrm{C}_{1}$ and $\mathrm{C}_{2}$ are often set to be 2 according to past experiences. The term $\mathrm{C}_{1} \operatorname{Rand}_{1}() \mathrm{x}$ (pbest $\mathrm{i}_{\mathrm{i}}-\mathrm{S}_{\mathrm{i}}^{\mathrm{k}}$ ) is called particle memory influence or cognition part which represents the private thinking of the itself and the term $C_{2} \operatorname{Rand}_{2}() \mathbf{x}$ (gbest $-S_{i}^{\mathbf{k}}$ ) is called swarm influence or the social part which represents the collaboration among the particles.

In the procedure of the particle swarm paradigm, the value of maximum allowed particle velocity $\mathrm{V}^{\text {max }}$ determines the resolution, or fitness, with which regions are to be searched between the present position and the target position. If $\mathrm{V}^{\max }$ is too high, particles may fly past good solutions. If $\mathrm{V}^{\mathrm{max}}$ is too small, particles may not explore sufficiently beyond local solutions. Thus, the system parameter $\mathrm{V}^{\max }$ has the beneficial effect of 
preventing explosion and scales the exploration of the particle search. The choice of a value for $\mathrm{V}^{\max }$ is often set at $10-20 \%$ of the dynamic range of the variable for each problem.

Suitable selection of inertia weight $\boldsymbol{W}$ provides a balance between global and local explorations, thus requiring less iteration on an average to find a sufficiently optimal solution. Since $\boldsymbol{W}$ decreases linearly from about 0.9 to 0.4 quite often during a run, the following weighing function of Eqn. (8) is used in Eqn. (6):

$$
W=W_{\text {max }}-\frac{W_{\text {max }}-W_{\min }}{\text { iter } r_{\text {max }}} \times \text { iter }
$$

Where, $\mathrm{W}_{\max }$ is the initial weight,

$\mathrm{W}_{\min }$ is the final weight,

Iter $_{\max }$ is the maximum iteration number,

iter is the current iteration number.

Eqn. (6) is used to calculate the particle's new velocity according to its previous velocity and the distances of its current position from its own best experience (position) and the group's best experience. Then the particle flies towards a new position according to Eqn. (7). The performance of each particle is measured according to a predefined fitness function, which is related to the problem to be solved.

\subsection{Implementation of PSO for ELD}

The main objective of ELD is to obtain the amount of real power to be generated by each committed generator, while achieving a minimum generation cost within the constraints. The evaluation function for evaluating the minimum generation cost of each individual in the population is adopted as follows:

$$
\text { Minimize } F_{T}=\sum_{i=1}^{d} F_{i}\left(P_{i}\right)
$$

The search procedure for calculating the optimal generation quantity of each unit is summarized as follows:

i) In the ELD problems the number of online generating units is the 'dimension' of this problem. The particles are randomly generated between the maximum and the minimum operating limits of the generators and represented using equation (9).

ii) To each individual of the population calculate the dependent unit output $\mathrm{P}_{\mathrm{du}}$ from the power balance equation and employ the B-coefficient loss formula to calculate the transmission loss $\mathrm{P}_{\mathrm{L}}$ using constraint satisfaction technique.

iii) Calculate the evaluation value of each individual $\mathrm{P}_{\mathrm{gi}}$ in the population using the evaluation function $\mathrm{f}$, given by equation (10).

iv) Compare each individual's evaluation value with its pbest. The best evaluation value among the pbest is identified as gbest.

v) Modify the member velocity $\mathrm{V}$ of each individual $\mathrm{Pg}_{\mathrm{i}}$ according to the following equation:

$$
\begin{gathered}
V_{i d}^{(t+1)}=w V_{i d}^{(t)}+c_{1} \operatorname{Rand}_{1}() \times\left(\text { pbest }_{i d}-P_{\text {gid }}^{(t)}\right)+c_{2} \text { Rand }_{2}() \times\left(\text { gbest }_{d}-P_{\text {gid }}^{(t)}\right) \\
\mathrm{i}=1,2, . \mathrm{n}, \mathrm{d}=1,2, . . \mathrm{m}
\end{gathered}
$$

Where, $\mathrm{n}$ is the population size, $\mathrm{m}$ is the generator units.

vi) Check the velocity constraints of the members of each individual from the following conditions:

$$
\begin{aligned}
& \text { if } V_{i d}^{(t+1)} \succ V_{d}^{\text {max }} \text {, then } V_{i d}^{(t+1)}=V_{d}^{\text {max }}, \\
& \text { if } V_{i d}^{(t+1)} \prec V_{d}^{\text {max }} \text {, then } V_{i d}^{(t+1)}=V_{d}^{\text {min }}, \\
& \text { where } V_{d}^{\text {min }}=-0.5 P_{d}^{\text {min }}, V_{d}^{\text {max }}=+0.5 P_{d}^{\text {max }}
\end{aligned}
$$

vii) Modify the member position of each individual $\mathrm{P}_{\mathrm{g} 1}$ according to Eqn.(12):

$$
P_{g_{i d}}^{(t+1)}=P_{g i d}^{(t)}+V_{i d}^{(t+1)}
$$

$P_{g_{i d}}^{(t+1)}$ must satisfy the constraints, namely the generating limits, described by Eqn. (5). If $P_{g_{i d}}^{(t+1)}$ violates the constraints, then $P_{g_{i d}}^{(t+1)}$ must be modified towards the nearest margin of the feasible solution.

viii) If the evaluation value of each individual is better than previous pbest, the current value is set to be pbest. If the best pbest is better than gbest, the best pbest is set to be gbest.

ix) If the number of iterations reaches the maximum, then go to step (x). Otherwise, go to step (ii).

$\mathrm{x}$ ) The individual that generates the latest gbest is the optimal generation power of each unit with the minimum total generation cost. 


\section{RESULTS AND DISCUSSION}

The procedure described in chapter three for the Particle Swarm Optimization based for solving ELD problems for the thermal power plant has been implemented using the developed PSO software on Matlab 7.1 for windows. The feasibility and the effectiveness of the method have been tested on the Nigerian thermal power plant. This was executed on hp laptop computer with the specification as follows, Processor: Intel ${ }^{\circledR}$ Celeron ${ }^{\circledR}$ CPU N2830 @ 2.16GHz, installed Memory (RAM): 2GB, system type: 64-bit operating system, hard disc: 500GB and operating system: windows 8.1. The results of the stimulation studies are presented.

[1] used the two approaches to solve this problem; micro genetic algorithm (MGA) and conventional genetic algorithm (CGA). [2] used differential evolution (DE) to solve the same problem. They all used three sets of power demand $\mathrm{P}_{\mathrm{D}}$ : $340 \mathrm{MW}, 850 \mathrm{MW}$ and $1150 \mathrm{MW}$.

PSO was applied to the above system for obtaining economic load dispatch of similar load requirements. PSO was implemented according to the flow chart shown. For each sample load, under the same objective function and individual definition, 20 trials were performed to observe the evolutionary process and to compare their solution quality and convergence characteristics.

\subsection{Simulation Results of the Nigerian Power System}

The developed PSO software for ELD problem was applied to the Nigerian power system whose single line diagram is shown in Figure 2. The Nigerian power system grid is essentially a 31-bus, 330-kV network interconnecting four thermal generating stations and three hydro stations to the various load points. The network data (Bus data, Generator data and Branch) were obtained from [1,2]. Table 1 presents the cost coefficients of the four Nigerian thermal power stations and their minimum and maximum loading limits.

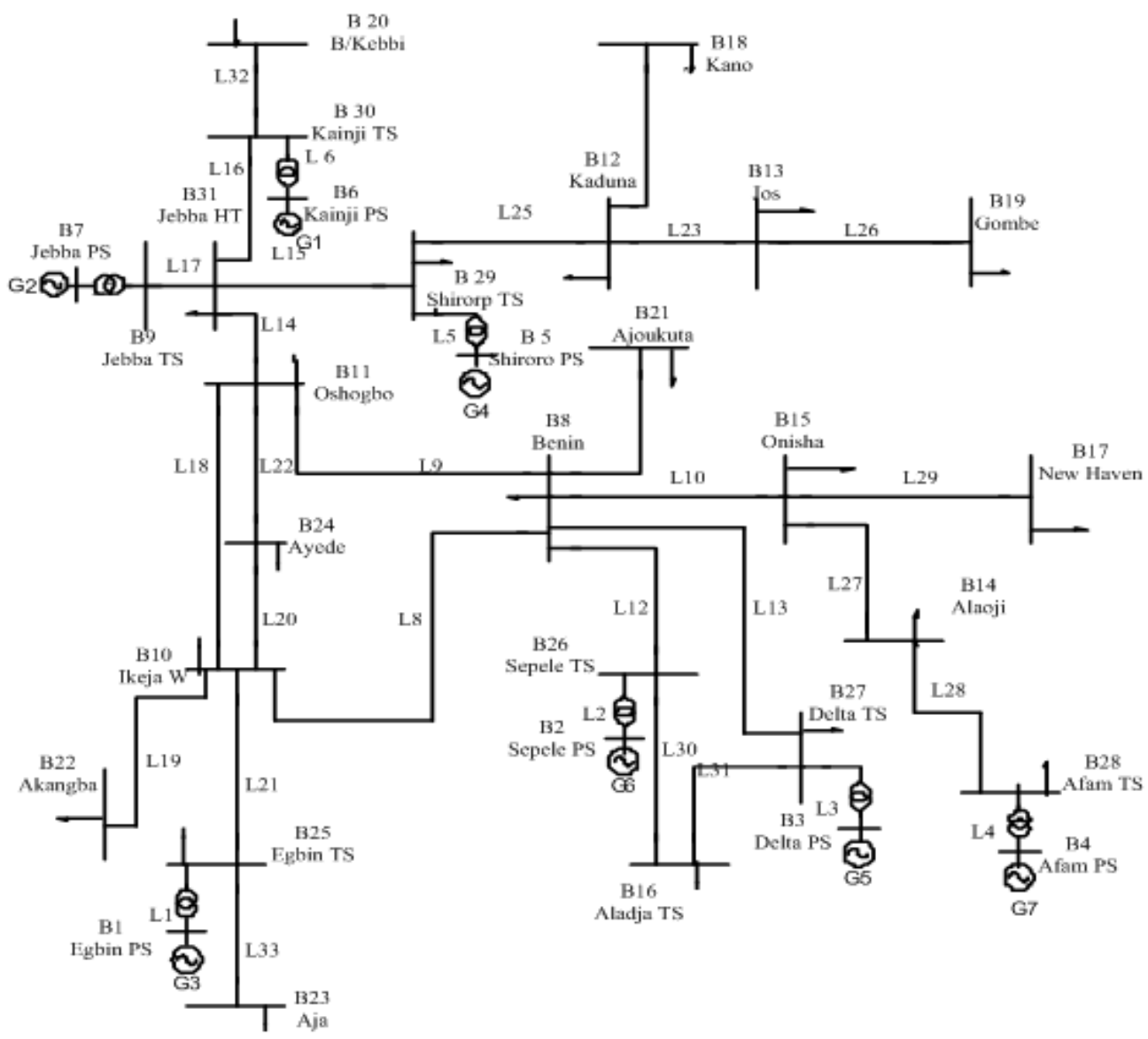

Figure 2: Nigerian 330 kV, 31- Bus Grid System

Table 1: Nigerian Thermal Power Plants Characteristics [1]

\begin{tabular}{|l|l|l|l|l|l|}
\hline Station & $\square$ & $\square$ & $\square$ & $\mathbf{P}_{\mathbf{G}}{ }^{{ }^{\operatorname{in}}}(\mathbf{M W})$ & $\mathbf{P}_{\mathbf{G}}{ }^{{ }^{\mathbf{a x}}}(\mathbf{M W})$ \\
\hline Sapele & 6929.0 & 7.84 & 0.13 & 137.5 & 550.0 \\
\hline Delta & 525.74 & -6.13 & 1.20 & 75.0 & 300.0 \\
\hline Afam & 1998.0 & 56.0 & 0.092 & 135.0 & 540.0 \\
\hline Egbin & 12787.0 & 13.1 & 0.031 & 275.0 & 1100.0 \\
\hline
\end{tabular}


Table 2: Results Comparison between MGA. CGA, DE and the Proposed PSO Techniques

\begin{tabular}{|l|l|l|l|l|}
\hline Power Station & MGA & CGA & DE & Proposed Method \\
\hline Sapele $\mathrm{P}_{\mathrm{G} 1}(\mathrm{MW})$ & 365.35 & 482.79 & 390.931 & 525.0564 \\
\hline Delta $\mathrm{P}_{\mathrm{G} 2}(\mathrm{MW})$ & 78.48 & 79.51 & 80.008 & 76.5315 \\
\hline Afam $\mathrm{P}_{\mathrm{G} 3}(\mathrm{MW})$ & 340.46 & 255.82 & 343.363 & 281.1126 \\
\hline Egbin $\mathrm{P}_{\mathrm{G} 4}(\mathrm{MW})$ & 878.39 & 844.56 & 848.078 & 839.5335 \\
\hline Kainji $\mathrm{P}_{\mathrm{G} 5}(\mathrm{MW})$ & 350 & 350 & 350 & 350 \\
\hline Shiroro $\mathrm{P}_{\mathrm{G} 6}(\mathrm{MW})$ & 490 & 490 & 490 & 490 \\
\hline Jebba $\mathrm{P}_{\mathrm{G} 7}(\mathrm{MW})$ & 450 & 450 & 450 & 450 \\
\hline Total Power Generated(MW) & 2952.80 & 2952.68 & 2952.38 & 3012.242 \\
\hline Total Power Demanded(MW) & 2823.10 & 2823.10 & 2823.10 & 2975.203 \\
\hline Total Power Loss $(\mathrm{MW})$ & 130.28 & 130.28 & 129.28 & 37.04 \\
\hline Total Cost(N/hr) & $114,521.33$ & $116,946.55$ & $107,430.00$ & $97,321.00$ \\
\hline
\end{tabular}

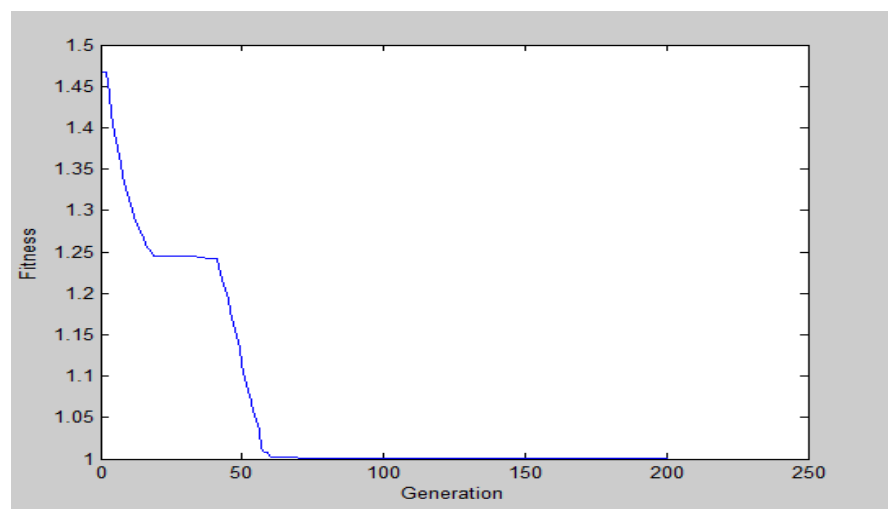

Figure 3: Convergence Characteristics of PSO

\section{CONCLUSION}

PSO method was successfully employed to solve the ELD problem. The comparison of results for the 31-bus Nigerian grid system clearly shows that the proposed PSO method was indeed capable of obtaining high quality solution efficiently for ELD problems. Figure 3 shows the convergence characteristics of the proposed method at the normal demand. The convergence is good since the algorithm takes few numbers of iterations to converge hence less computation time. From the results obtained, the proposed PSO technique minimizes the total production cost and transmission losses better than MGA and CGA, except in some cases where the DE also performed equally good.

\section{REFERENCES}

[1]. Haruna, Y. S. (2004). Comparison of Economic Load Dispatch using Genetic Algorithm and Classical Optimization Method. Unpublished M.Eng. Thesis, Abubakar Tafawa Balewa University, Bauchi.

[2]. Awodiji, O.O., Bakare, G. A., Aliyu, U. O. (2014). Short Term Economic Load Dispatch of Nigerian Thermal Power Plants Based on Differential Evolution Approach. IJSER. Vol 5 Issue 3.

[3]. Jagadeesh, G. (2011). Multi Objective Economic Dispatch Using Pareto Frontier Differential Evolution. International Journal of Engineering Science and Technology (IJEST). ISSN : 0975-5462 Vol. 3 No. 10.

[4]. Faheemullah, S., Pervez, H., Shaikh, M., Mirani, M. and Aslam, U. (2012). Multi Criteria Optimization Algorithm for Economic Dispatch Complications for Sustainable Interconnected Power System. International Journal of Computer Applications (0975 8887), Volume 50 - No.4.

[5]. Ismail, M., Nur, H. F. I., Mohd, R. K., Muhammad, K. I., Titik. K. A., and Mohd, R. A. (2008). Ant Colony Optimization (ACO) Technique in Economic Power Dispatch Problems. Proceedings of the International Multi Conference of Engineers and Computer Scientists 2008. Vol II, pp 19-21.

[6]. Hardiansyah, Junaidi and Yohannes, M. S. (2012). Solving Economic Load Dispatch Problem Using Particle Swarm Optimization Technique, I.J. Intelligent Systems and Applications, Vol. 12, pp 12-18.

[7]. Senthilkumar, S. and Vijayalakshmi, V. J. (2013). A New Approach to the Solution of Economic Dispatch Using Particle Swarm Optimization with Simulated Annealing. International Journal on Computational Sciences \& Applications (IJCSA) Vol.3, No.3.

[8]. Damoon, R. D., Asef, G. and Seyyed, M. H. (2016). Solving Static Economic Load Dispatch Using Improved Exponential Harmony Search Optimization. Australian Journal of Electric and Electronics Engineering, Vol. 13, Issue 2.

[9]. Makoju, J. (2003). Resuscitating the Nigerian Power Sector: The Resuscitating and Privatisation Reforms. COREN Assembly, Abuja.

[10]. Rahul, D., Nikita, G. and Harsha, S. (2014). Economic Load Dispatch Problem and MATLAB Programming of Different Methods. International Conference of Advance Research and Innovation (ICARI-2014).

[11]. Susheel, K. D., Achala, J. and Huddar, A. P. (2015). IOSR Journal of Electrical and Electronics Engineering (IOSR-JEEE), Vol. 10, Issue 2 Ver. III, PP 27-32.

[12]. Sonal, A. and Devendra, D. (2016). Power Economic Dispatch of Thermal Power Plant Using Classical Traditional Method. International Journal for Research in Applied Science \& Engineering Technology (IJRASET), Vol. 4 Issue II, pp2321-9653.

[13]. Bakare, G. A. (2001). Removal of overloads and Voltage problems in Electric Power Systems using Genetic Algorithm/Expert System Approaches, Shaker Verlag, Aachen Germany. 